\title{
O SENTIDO DO TRABALHO PARA PESSOAS COM DEFICIÊNCIA
}

MICHELLE PINTO DE LIMA

Mestra em Administração pelo Departamento de Administração da Universidade Federal de Lavras (Ufla). Professora do Departamento de Gestão e Negócios do Instituto Federal de Educação, Ciência e Tecnologia do Piauí (IFPI). Praça da Liberdade, 1.597, Centro, Teresina - PI - Brasil - CEP 64000-000 E-mail:michelle17pi@gmail.com

NATHÁLIA VASCONCELOS TAVARES

Mestre em Administração pelo Departamento de Administração e Economia da Universidade Federal de Lavras (Ufla).

Professora do Departamento de Administração da Faculdade Adventista de Minas Gerais (Fadminas).

Rua Joaquim Gomes Guerra, 590, Centro, Lavras - MG - Brasil - CEP 37200-000

E-mail: nathaliavt2006@yahoo.com.br

MOZAR JOSÉ BRITO

Doutor em Administração pela Faculdade de Economia, Administração e Contabilidade da Universidade de São Paulo (FEA-USP).

Professor do Departamento de Administração e Economia da Universidade Federal de Lavras (Ufla). Campus Universitário, Caixa Postal 3.037, Lavras - MG - Brasil - CEP 37200-000

E-mail: mozarbrito@gmail.com

\section{MÔNICA CARVALHO ALVES CAPPELLEE}

Doutora em Administração pelo Departamento de Administração da Universidade Federal de Minas Gerais (UFMG).

Professora do Departamento de Administração e Economia da Universidade Federal de Lavras (Ufla).

Campus Universitário, Caixa Postal 3.037, Lavras - MG - Brasil - CEP 37200-000

E-mail: edmo@dae.ufla.br

Este artigo pode ser copiado, distribuído, exibido, transmitido ou adaptado desde que citados, de forma clara e explícita, o nome da revista, a edição, o ano, e as páginas nas quais o artigo foi publicado originalmente, mas sem sugerir que a RAM endosse a reutilização do artigo. Esse termo de licenciamento deve ser explicitado para os casos de reutilização ou distribuição para terceiros. Não é permitido o uso para fins comerciais. 


\section{RESUMO}

Esta pesquisa tem o objetivo de analisar o sentido do trabalho para as pessoas com deficiência (PcD). Optou-se por adotar a perspectiva da psicologia social para compreender a produção de sentidos relacionados ao trabalho devido à sua relação com a produção da subjetividade dos sujeitos. A dimensão do trabalho como realidade social, como bem afirma Dejours (2004), é essencial à atividade humana, contribuindo para a satisfação de necessidades não apenas econômicas, mas também psicológicas e sociais. Para as PcD, o estudo dessa atribuição de sentidos se torna instigante, visto que o trabalho tem sido considerado uma importante via de inclusão social dessas pessoas na sociedade. Para o desenvolvimento da pesquisa qualitativa que deu origem a este artigo, optou-se pela aplicação do método de análise das práticas discursivas, cujos pressupostos ontológicos e epistemológicos estão ancorados na abordagem sociocontrucionista descrita por Spink (2004). Adotou-se a pesquisa qualitativa para a compreensão da produção de sentidos, com a análise das práticas discursas. O construcionismo social foi utilizado como método da pesquisa. Foram realizadas entrevistas em profundidade com pessoas com deficiência inseridas no mercado de trabalho escolhidas por meio da técnica bola de neve. Para o procedimento, realizou-se uma adaptação do recurso dos mapas de associação de ideias utilizados por Spink (I999). A análise dos resultados permitiu a elaboração das categorias que revelam os sentidos do trabalho para as pessoas com deficiência, entre as quais se destacam o trabalho como meio de sobrevivência, a necessidade de ser útil à sociedade, de garantia da independência financeira e pessoal. Observou-se, nas produções discursivas, a centralidade do trabalho na vida de todos eles, estando, para alguns, mais relacionado à sobrevivência e, para outros, à inserção social. As vivências no trabalho estão relacionadas ao sentimento de capacidade e utilidade para com a sociedade. Este trabalho permitiu compreender que as regularidades encontradas nos repertórios discursivos remetem o sentido do trabalho para o exercício pleno de cidadania. 


\section{PALAVRAS-CHAVE}

Trabalho; Deficiência; Diversidade; Sentidos; Inclusão.

\section{INTRODUÇÃO}

A temática do sentido no trabalho ainda é pouco explorada no Brasil, sendo a maior parte dos estudos baseada nas investigações desenvolvidas pelo Meaning of Work International Research Team (I987) e, mais recentemente, por Morin (200I). No entanto, conforme destacam Tolfo e Piccinini (2007), muitos autores ressaltam que as variáveis adotadas naquelas pesquisas destacam apenas a centralidade, as normas sociais e os resultados valorizados do trabalho, o que torna importante a adoção de outras perspectivas de estudo para compreender a atribuição de sentidos do trabalho pelos sujeitos. É preciso considerar uma análise do trabalho que extrapole a simples associação entre cidadania e emprego remunerado, como apontam Barnes e Mercer (2005).

Como alternativa, ressaltam-se as abordagens qualitativas adotadas para as práticas discursivas que não estão voltadas para relações de causa e efeito entre variáveis, mas para a produção de sentidos por meio dos discursos. Optou-se por adotar a perspectiva teórica da psicologia social para compreender a produção de sentidos relacionados ao trabalho para pessoas com deficiência $(\mathrm{PcD})$, uma vez que, sob essa ótica, a atribuição de sentidos resulta da interação entre variáveis pessoais e ambientais, podendo se revelar distintas entre os entrevistados. O sentido que o trabalho tem para cada indivíduo é construído por meio da compreensão da subjetividade individual, sendo variante, uma vez que os indivíduos se apropriam de vários elementos relativos ao trabalho e os ressignificam.

As razões que apontam para a necessidade de explorar o sentido do trabalho de pessoas com deficiência são justificadas pelos efeitos que o trabalho provoca na vida dessas pessoas, uma vez que elas saem da condição de isolamento social e da dependência de outros para criar seus próprios vínculos em outros espaços, com outras pessoas e desempenhando outras atividades. Qual seria o sentido do trabalho para as pessoas que tiveram acesso a ele por meio de uma imposição legal? O sentido do trabalho para uma pessoa com deficiência pode representar uma dimensão interdependente da percepção que ela tem de si mesma e da própria vida (CARVALHO-FREITAS; MARQUES; SCHERER, 2004). Julga-se importante conhecer os discursos produzidos a respeito do sentido atribuído ao trabalho para compreender como suas práticas e vivências contribuem para a produção desse sentido. 
Para tanto, a seção 2 apresenta a diferenciação entre significado e sentido do trabalho e as relações entre o trabalho, subjetividade e pessoa com deficiência. Na seção 3, indicam-se os procedimentos metodológicos utilizados para a obtenção e análise dos discursos. Nas seções 4 e 5, analisaram-se os repertórios discursivos produzidos na constituição dos sentidos relacionados ao trabalho de PcD. Por último, fazem-se as considerações finais.

\section{SIGNIFICADO, SENTIDO E CONSTRUCIONISIMO SOCIAL}

O construcionismo social considera o discurso sobre o mundo como um artefato de intercâmbio social, e não apenas como um reflexo. Na pesquisa, ocupa-se de explicar os processos pelos quais as pessoas descrevem, explicam ou, de alguma forma, dão conta do mundo em que vivem (incluindo a si mesmas). Para isso, o momento da interação entre as pessoas é tomado como parte do processo para a produção de sentidos, sendo o lócus da explicação localizado externamente, de modo a enfatizar os processos e as estruturas da interação humana. No construcionismo, a compreensão do sentido atribuído a partir do discurso não é obtida apenas pela observação, mas também pelo contato com o outro, interagindo com ele e observando o contexto em que essa interação com outros ocorre.

Essa investigação construcionista social procura enfatizar o sentido que as PcD dão ao trabalho. Por isso, houve a necessidade de fazer a diferenciação entre sentido e significado, uma vez que, segundo Aguiar (2006), muitos trabalhos os tratam como sinônimos, embora não possam ser compreendidos desvinculados um do outro, pois um não é sem o outro.

A relação entre significado e sentido é tratada por Vygotsky (200I), que, apesar de ser construtivista, adota considerações similares ao que é tomado pelo construcionismo para a interpretação dos termos. Para ele, as palavras/signos são o ponto de partida para a busca do sentido, para uma aproximação com a subjetividade do sujeito. O enlace entre significado e sentido é reconhecido quando vincula o pensamento com a ação. A atividade humana seria impregnada pelo signo, sobretudo o verbal. Vygotsky (200I) argumenta que o que é internalizado não é o gesto como materialidade do movimento, mas a sua significação, a qual tem o poder de transformar o material em cultural. Portanto, os significados se relacionam com produções históricas e sociais, pois são eles que permitem a socialização das experiências (AMARAL, I994a).

Embora sejam razoavelmente estáveis, os significados se transformam no movimento histórico pelo processo dialético, ou seja, pela internalização de normas e práticas sociais que afetam os processos psicológicos que os internalizam e 
os produtos das interações sociais. Assim como Vygotsky (200I), que considera a dinamicidade dos significados na linguagem em virtude do processo de desenvolvimento humano, Aguiar (2006, p. I4) argumenta que, para compreender melhor o sujeito, os significados são o ponto de partida, pois sabe-se que eles contêm mais do que aparentam e que, por meio de um trabalho de análise e interpretação, pode-se caminhar para zonas mais profundas, ou seja, para as zonas de sentido.

O sentido tem uma formação dinâmica, complexa, constituído pela articulação dos eventos psicológicos que o sujeito produz perante a realidade. Para Vygotsky (200I, p. 465), a significação é atribuída no contexto do uso da palavra e nas condições de interação dos falantes. A variação dos contextos de ocorrência faz com que os sentidos sejam ilimitados. Além da dependência contextual, o sentido atribuído depende da interpretação do mundo que cada pessoa faz, o que a torna vinculada à sua estrutura interna de personalidade.

O significado da palavra corresponde ao um signo, enquanto o sentido é inesgotável, pois varia conforme o contexto. É o sentido que destaca a singularidade historicamente constituída pelo sujeito e se torna a melhor forma de aproximação com a subjetividade expressa por ele. Para Leontiev (2004), o homem encontra um processo de significações pronto, elaborado historicamente e apropria-se dele, atribuindo-lhe um sentido pessoal que é determinado pelo motivo de sua ação. Com base nesses argumentos, González Rey (2003, p. 205) considera que o sentido subverte o significado, pois não está submetido a uma lógica racional externa.

O construcionismo considera o sentido como uma construção social, um empreendimento coletivo, interativo, por meio do qual as pessoas constroem os termos a partir dos quais compreendem as situações e os fenômenos à sua volta, e lidam com eles, levando em consideração a dinâmica das relações historicamente datadas e culturalmente localizadas, como afirma Spink e Medrado (2004, p. 4I). De acordo com a perspectiva psicossocial, a produção de sentidos não é uma atividade cognitiva individual, muito menos uma simples reprodução de modelos já predeterminados. Trata-se de uma prática social, dialógica, que implica a linguagem em uso, tomada como fenômeno sociolinguístico. Por meio da linguagem, as práticas sociais produzem sentido.

Os construcionistas sociais focalizam sua atenção nos processos microssociais, defendendo a compreensão humana a partir da esfera relacional e nas práticas discursivas, que, segundo eles, constituem a base de qualquer conhecimento. Miller (I999) afirma que o construcionismo social é uma abordagem de conhecimento que enfatiza a forma como os sentidos de realidade de indivíduos e grupos são construídos e sustentados. Além disso, esses sentidos provocam uma mudança no modo como as pessoas interpretam aspectos de sua vida e experiências. $\mathrm{O}$ construcionismo social trata os sentidos da estrutura social como intimamente 
ligados ao conhecimento e às experiências do sujeito, aos mundos da vida cotidiana, bem como à linguagem que eles usam para descrever suas experiências.

Contrariamente ao construtivismo que prega a construção do significado por uma mente individual, no construcionismo social o significado é produzido na interação entre as pessoas. É o que as pessoas fazem juntas que viabiliza a existência de determinadas linhas de ação e interpretação. O potencial de significação está no relacionamento e na forma como as pessoas enunciam e suplementam suas conversas, coordenando suas ações. À medida que se compartilha determinada descrição de mundo, gera-se possibilidade de ação e de realidade.

Ao focalizar especificamente o trabalho, Simoni (I996) aponta que o sentido vem sendo tratado de forma polissêmica. Ele pode significar a forma pela qual homens e mulheres conseguem garantir sua subsistência e sobrevivência. Pode significar também a atividade que coloca em contato várias pessoas e possibilita a criação de laços sociais e afetivos de união (ou desunião). Pode ser também a oportunidade de desenvolvimento de sua habilidade técnica maior. Pode, ainda, significar o ponto de referência de cada pessoa para se situar no seu contexto social e histórico. Pode ser tudo isso e mais alguma coisa.

Tratar da questão da produção da significação, do sentido do trabalho pelos indivíduos também exige uma reflexão com base na psicodinâmica do trabalho de Dejours (I993), considerada uma das principais teorias que subsidiam os estudos da subjetividade e do trabalho. Esse olhar vem contribuindo para a análise da relação subjetividade e trabalho e define como seu foco de interesse a análise dinâmica dos processos psíquicos mobilizados pelo confronto do sujeito com a realidade do trabalho.

Dejours (I999, p. 207) defende a concepção de um sujeito que é responsável por seus atos, capaz de pensar, de interpretar os sentidos da situação em que se encontra, de deliberar ou de decidir e agir. Esse sujeito é dotado de inteligência, a qual é tratada não apenas como competência cognitiva, mas também como uma inteligência que compreende as coisas e a situação. Com base nisso, a PcD foi considerada neste estudo sobre o sentido do trabalho, pois, segundo Batista, Pereira e Diniz (I997), o encontro desse sujeito com o trabalho passa pelo rompimento de mitos para mostrar que é capaz. Primeiro, precisa romper com o mito social que o vê como alguém improdutivo e com um mito familiar que o vê como dependente, como quem precisa sempre de cuidados especiais e não reúne as condições de desenvolver um trabalho que represente realização ou satisfação dos desejos.

Com base no pressuposto de que o trabalho ocupa papel fundamental na construção do sujeito, no exercício da cidadania e na constituição da sua subjetividade, ele será tomado de uma investigação mais profunda, na tentativa de compreender os sentidos que tem para as pessoas com deficiência. 


\section{TRABALHO, SUBJETIVIDADE E PESSOA COM DEFICIÊNCIA}

Para compreender o sentido, é importante focalizar o papel do trabalho na produção da subjetividade do trabalhador. Nas palavras de Heller (2004), a vida cotidiana é a vida do homem. Nela, o homem expressa toda a sua individualidade, todos os sentidos, suas capacidades intelectuais, habilidades, sentimentos e ideologias, estando enraizada aí sua subjetividade. É pela inserção nas organizações e pelo exercício do seu trabalho que homens e mulheres expressam suas ações e revelam suas subjetividades.

Enriquez (200I, p. 58) reforça a importância do trabalho como fator de equilíbrio psíquico na vida das pessoas, afirmando que o homem sem trabalho ou não reconhecido em seu trabalho, ou ainda não encontrando nenhum interesse em seu trabalho, está próximo da depressão e comumente chega a esse ponto de ruptura. Em nossa sociedade, o trabalho é um modo privilegiado de fazer uma obra, de existir, de ter ou pensar ter uma identidade.

A relação do trabalho com a subjetividade é, portanto, um campo interdisciplinar que se caracteriza pela importância das vivências e experiências adquiridas no mundo do trabalho e das representações que os trabalhadores fazem desse cotidiano. Revela a forma como o trabalhador, como sujeito, vive e dá sentido às suas experiências no trabalho. Para Nardi, Tittoni e Bernardes (I997), pensar a subjetividade relacionada ao trabalho implica pensar os modos como as experiências do trabalho contribuem para formar modos de agir, pensar, sentir e trabalhar.

Para Nardi, Tittoni e Bernardes (I997), o trabalho é considerado um espaço no qual se interseccionam dimensões da cultura, em que diferentes variantes sociais - classe, gênero, raça, idade etc. - atravessam sua prática. O trabalho como vivência subjetiva admite múltiplas interações entre diferentes sujeitos em diferentes condições (homem, mulher, negro, pobre, com deficiência ou não, com melhores currículos ou não, com diferentes modos de pensar, sentir, trabalhar), evocando o entrelaçamento de diferentes elementos e modos de produzir e trabalhar.

Heller (2004, p. 20) aponta que o trabalhador pertence a um corpo, o qual está apoderado pela direção produtiva materializada nas relações de trabalho. Esse trabalhador dotado de subjetividade "é sempre, simultaneamente, ser particular e ser genérico", pois, ao mesmo tempo que é sujeito do mundo, é sujeito no trabalho, na sua forma de pensar e de agir. Por mais que seja "o sujeito no trabalho", ele não se desprende totalmente do seu meio social.

Dejours (I993) afirma que a atividade profissional não é só um modo de ganhar a vida, mas também uma inserção social em que os aspectos psíquicos e físicos estão fortemente implicados. Ao status social, ao exercício de tal atividade, associam-se uma roupa específica, um vocabulário particular e um lugar. Esses 
elementos também fazem parte importante do dia, da rotina e da vida do indivíduo. Essas diferentes relações do indivíduo com o seu trabalho permeiam o seu desenvolvimento. Trabalhar implica gestos, saber-fazer, engajamento do corpo, mobilização da inteligência, capacidade de refletir, de interpretar e de reagir às situações; é o poder de sentir, de pensar e de inventar (DEJOURS, 2004).

O corpo está sempre envolvido em primeiro lugar no trabalho. Nem mesmo o trabalho intelectual escapa a esse envolvimento, pois não há experiência afetiva sem um corpo para experimentá-lo: "A habilidade, a destreza, a virtuosidade e a sensibilidade técnica passam pelo corpo, se capitalizam e se memorizam no corpo e se desenvolvem a partir do corpo" (DEJOURS, 2004, p. 29). É no corpo que a inteligência habita, e, por meio desta, podem-se desenvolver as habilidades necessárias para fazer o trabalho. A formação da inteligência do corpo não acontece de forma inata, e sim por meio da relação prolongada e perseverante do corpo com a tarefa.

Dejours (2004) ainda ressalta que o que há de essencial no trabalho não pertence ao mundo visível, pois a essência do trabalho contém partes afetivas. A psicodinâmica do trabalho leva em consideração que o trabalho não é redutível a uma atividade de produção no mundo objetivo, mas uma possibilidade de transformar a si mesmo, ocasião em que a subjetividade é sempre testada, pois trabalhar também é viver junto.

O trabalho também é uma possibilidade de inserção social, devido ao encontro do trabalhador com muitos outros dentro do mesmo espaço ou fora dele, deixando de ser apenas uma atividade para ser também uma forma de relação social. Participar desse mundo social possibilita o aprimoramento da subjetividade, pois tornar visível o saber-fazer, a inteligência e a experiência de trabalhar é uma forma de obter o reconhecimento dos outros, receber o julgamento dos outros. Para deixar de ser invisível e ser reconhecido, o trabalhador precisa estar em cooperação com seus pares.

A dimensão do trabalho como realidade social, como bem afirma Dejours (2004), é essencial à atividade humana, contribuindo para a satisfação de necessidades não apenas econômicas, mas também psicológicas e sociais. Por essa razão, a questão da inserção das pessoas com deficiência no mercado de trabalho tem sido alvo de muitas políticas públicas que visam facilitar a entrada delas nas organizações. Além de terem o direito de buscar uma qualidade de vida melhor para si, as pessoas com deficiência possuem habilidades e competências que podem ser expressas no trabalho e por meio dele.

No entanto, essa discussão sobre a inclusão ganhou maior relevância quando da aprovação de leis específicas que tentam assegurar o direito ao trabalho das pessoas com deficiência, obrigando empresas a reservar vagas para elas. No Brasil, a Lei $n^{\circ} 8 . I I 2$, de II de dezembro de I990, que define em até $20 \%$ o per- 
centual de vagas em concursos públicos, e a Lei n 8.213, de 24 de julho de I99I, que determina uma cota de vagas para a pessoa com deficiência, variando de $2 \%$ a 5\%, nas empresas privadas com mais de ioo funcionários (BRASIL, I999a, I999b), impulsionaram a contratação de pessoas com deficiência. Suzano et al. (2008), em um trabalho que analisa a produção acadêmica nacional dos últimos 20 anos sobre a inserção da pessoa portadora de deficiência no mercado de trabalho, afirmam que um maior interesse nessa temática de PcD foi constatado após a lei, o que pode estar relacionado a um interesse das empresas em conhecer mais a respeito da pessoa com deficiência para saber como contratá-la e gerir seu trabalho dentro das organizações.

Para Barnes e Mercer (2005), as políticas que facilitam a entrada de PcD no mercado de trabalho centram-se em programas de educação e treinamento, além de vários incentivos para os empregadores contratarem essas pessoas. Além do ganho de incentivos, McLaughli, Bell e Stringer (2004) ressaltam que a atitude de contratação das $\mathrm{PcD}$ pode gerar impacto nas organizações quanto ao nível de aceitação dessas pessoas, uma vez que diminui a distância social entre elas e os funcionários que não têm deficiência, possibilitando a quebra de julgamentos discriminatórios tradicionalmente atribuídos a esses indivíduos e fornecendo ferramentas necessárias para possibilitar o trabalho eficiente dessas pessoas, transformando deficiências em habilidades. Carvalho-Freitas (2009) ressalta benefícios apontados por gerentes com a contratação de PcD: melhoria da imagem da empresa entre clientes e funcionários, o que tem a ver com a responsabilidade socioambiental dela.

A adição de mulheres, estrangeiros e minorias à força de trabalho representa uma diversidade de cultura, raça ou origem nacional. A fim de responder a esses desafios, os empregadores terão de aprender a valorizar a diversidade e contratar funcionários de fontes não tradicionais. Para Fleury (2000), a organização gera valor quando administra a diversidade, pois há um redirecionamento das relações com os clientes internos, externos e com a sociedade. A diversidade presente na comunidade está representada na empresa, com suas maiorias e minorias. Para Esteves (2000), contratar e valorizar diferentes representantes da comunidade torna o ambiente de trabalho mais parecido com a sociedade à sua volta.

As pessoas com deficiência têm conquistado mais espaço no mercado de trabalho. De acordo com os dados do Ministério do Trabalho e Emprego, o número de PcD contratadas no Brasil subiu de 22.3I4, em 2007, para 25.844, em 2008. Um crescimento superior a I5\%. Dados da Delegacia Regional do Trabalho em São Paulo (DRT-SP) mostram que, desde a criação do programa de inclusão de pessoa com deficiência, em 200 I, cerca de 47 mil pessoas foram empregadas (dados até maio de 2006). Apesar do aumento da oferta de vagas como cumprimento da exigência imposta pela lei, a falta de informação sobre a potencia- 
lidade para o trabalho da pessoa com deficiência ainda persiste, como afirmam Tanaka e Manzini (2005), aliada à crença de que ela não irá corresponder ao ritmo imposto pela produtividade no emprego. Para os autores, a falha no processo de formação e qualificação profissional é o fator que dificulta a inserção de PcD no mercado de trabalho, aliada à falta de condições estruturais e funcionais das empresas para recebê-las. A força da lei que obriga as empresas a contratar pessoas com deficiência propiciou um cenário marcado pela coexistência de realidades diferentes, pois o acesso ao trabalho formal, antes reservado apenas para o trabalhador física e mentalmente "normal", também é direito das PcD.

Ao estabelecerem padrões de normatividade, previsibilidade, processos homogeneizados, as organizações exigem que seus funcionários se adaptem à estrutura predefinida, ficando segregados aqueles impossibilitados disso, o que contribui para gerar uma diferenciação social e a legitimação de estereótipos e estigmas, que se interpõem na relação de um sujeito com outro, alvo de segregação. Para Amaral (I994a), a opinião sobre o outro e a modalidade da relação ficam definidas a priori pelo estereótipo, indicando as possibilidades e impossibilidades dessa relação, inclusive no que tange às expectativas acerca do outro. Sendo negada essa possibilidade de participar da construção do mundo laboral, restam àqueles que não preenchem as condições da normalidade as atividades mecânicas. Potencialidades e limites singulares da PcD não são levados em consideração, e diferenças biológicas, psicológicas ou físicas acabam por se transformar em diferenças sociais.

Goffman (I988) compreende o estigma como um conceito que se funda numa relação em que são considerados atributos depreciativos de uma pessoa. Ele seria construído sobre a identidade social virtual (constituída por uma imputação feita por outra pessoa) e a identidade social real (constituída pelas características que o sujeito acredita ter ou acredita ser). O estigma, então, pode ser utilizado como critério de diferenciação e distinção das pessoas com deficiência nos espaços sociais, uma vez que há a identificação do atributo (deficiência) e sua utilização na relação como forma de desvalorização desse outro (PcD).

Se para as PcD ainda se apresentam todas essas dificuldades como forma de obstáculos para a sua inclusão no mercado de trabalho, o sentido atribuído ao trabalho para aqueles que conseguiram ter um emprego formal, ou não, seria diferente? Como elas próprias avaliam o sentido do trabalho em suas vidas? Quando o sentido do trabalho é atribuído, uma dimensão afetivo-emocional, que atua influenciando e transformando sua interpretação, também vem à tona. Investigar os discursos produzidos por esse público é fundamental para aproximar-se da sua subjetividade, de forma que tal compreensão seja fonte de estímulo para que políticas públicas e práticas organizacionais atendam melhor aos seus anseios e tragam novos referenciais para ampliar as possibilidades de interação no e sobre o trabalho. 


\section{PROCEDIMENTOS METODOLÓGICOS}

Para compreender o sentido do trabalho para a PcD, optou-se por uma pesquisa qualitativa para a investigação da produção de sentidos do trabalho, utilizando como método a análise das práticas discursivas proposto por Spink e Medrado (2004). O caminho para o entendimento da produção de sentidos do trabalho está situado nas práticas discursivas, foco central da análise na abordagem construcionista.

Partiu-se do pressuposto, como recomenda a abordagem construcionista, de que a linguagem é tomada como prática social. O enunciado dessas pessoas é uma unidade do ato de comunicação. Para Spink e Medrado (2004), os sujeitos sociais fazem uso de diferentes formas de linguagem e das enunciações para construir seus repertórios interpretativos, que servem de mecanismo de produção de sentidos acerca da realidade sócio-histórica em que estão inseridos. Esses repertórios, considerados unidades de práticas discursivas, é uma complexa corrente de outros enunciados. Ao produzi-los, o sujeito utiliza um sistema de linguagem e de enunciações preexistentes para dar sentido às coisas, fazendo uso de repertórios interpretativos que são unidades de construção das práticas discursivas. São marcados por termos, metáforas, sinais, figuras de linguagem e imagens utilizados nas conversações que dão origem à produção dos sentidos acerca da realidade.

As pessoas empregam os repertórios interpretativos para justificar a sua visão de mundo e as suas ações e manter a legitimidade dos seus pontos de vista no momento da interação social. Para Potter e Wheterell (i987), a identificação e a categorização desses repertórios podem contribuir para a descoberta, a apreensão e a interpretação de alguma versão particular de um evento para validar ou questionar os próprios comportamentos e para manter a credibilidade na interação. A identificação dos sentidos favorece a possibilidade de categorização, dando maior visibilidade ao processo de produção de sentido.

Neste estudo, a pesquisa qualitativa veio atender adequadamente ao processo de investigação dos sentidos para as PcD. Tal escolha metodológica se justificou por se saber que a produção do fenômeno social se assenta em um espaço de complexas relações de sentido, as quais não podem simplesmente ser reduzidas à operacionalização de variáveis, dada sua dinamicidade no contexto social e ressignificação por cada sujeito.

\section{PESQUISA DE CAMPO E PROCESSO DE COLETA DE INFORMAÇÕES}

No mês de julho de 20I0, foram realizadas entrevistas semiestruturadas com dez pessoas com algum tipo de deficiência, sendo seis homens e quatro mulheres 
com idade variando de I 6 a 50 anos. A amostra exigia pessoas com deficiência inseridas no mercado de trabalho, e a técnica de acesso aos entrevistados ocorreu de forma que um indicava outro para ser entrevistado (bola de neve). Todos os participantes eram moradores da região metropolitana da cidade de São Paulo, com diferentes tipos de deficiência: quatro entrevistados possuíam deficiência física; dois, deficiência visual; um, deficiência auditiva; e três eram pessoas com deficiência mental. Estas últimas pertenciam à mesma empresa. A maior parte dos entrevistados, sete pessoas, já havia tido outras experiências de trabalho, em outros locais, exercendo outras funções. Apenas no caso de três pessoas, as que apresentavam deficiência mental, tratava-se do primeiro emprego. Metade dos entrevistados havia passado por algum tipo de formação profissional específico para pessoas com deficiência. Tais cursos foram oferecidos pela prefeitura e pelo Senai.

Todos os participantes ocupavam vagas destinadas a PcD. Apenas três entrevistados (com deficiência física) tinham ensino médio completo e julgavam ocupar um cargo compatível com o seu nível de escolaridade, com chances de ascender na hierarquia da empresa (instituição financeira). A outra pessoa com deficiência física era manobrista em um estacionamento da cidade. O deficiente auditivo e os cegos ocupavam o cargo de assistente administrativo. Os demais, com deficiência intelectual, estavam na experiência do primeiro emprego e ocupavam o cargo de auxiliar de serviços gerais. Todos trabalhavam seis horas por dia.

A seguinte pergunta foi feita a todos os entrevistados: "Qual é o sentido do trabalho para você?”. De acordo com a fluência verbal de cada um deles, novas perguntas surgiam para esclarecer alguns aspectos sobre o que estava sendo falado pelo entrevistado. Para entrevistar a pessoa com deficiência auditiva, obteve-se o auxílio de um intérprete de libras. Especialmente para as pessoas com deficiência mental, maiores esclarecimentos e novas informações foram solicitados para permitir melhor compreensão do conteúdo apresentado por elas.

Tendo em vista a centralidade dos repertórios interpretativos na abordagem construcionista para a compreensão da produção de sentidos, a análise privilegiou a linguagem verbal e a dialogia implícita na produção de sentidos e o encadeamento das associações de ideias (SPINK; LIMA, 2004, p. IO6). Tal análise iniciou-se com a releitura do conjunto de informações coletadas de maneira a não categorizar ou mesmo classificar os dados. A partir das leituras, foi realizada a transcrição do texto de cada entrevista por meio da escrita das gravações, verificando-se os temas abordados. Todas as respostas foram listadas, com a identificação das mais frequentes. Isso permitiu o estabelecimento de categorias temáticas capazes de abranger a totalidade dos discursos dos entrevistados.

Para o procedimento de análise, realizou-se uma adaptação do recurso dos mapas de associação de ideias utilizados por Spink (I999). Para a elaboração do 
mapa, as perguntas formuladas guiaram a disposição das respostas. Tal disposição procurava identificar a construção dos discursos e dos repertórios utilizados nessa construção e a dialogia implícita na produção de sentidos. Para consecução desse objetivo, o diálogo foi mantido intacto, sem fragmentação, apenas sendo deslocado para as colunas previamente definidas em função dos objetivos da pesquisa. Os mapas de associação de ideias como recurso de análise permitem a visualização do encadeamento das associações de ideias das pessoas com deficiência entrevistadas. Considerando a importância da ordem das associações, quatro colunas foram utilizadas para a construção dos mapas.

Considerando que a entrevista associativa é composta de temas e subtemas, a primeira coluna dos mapas serviu de referência para a introdução de cada novo núcleo associativo, pois são as perguntas feitas pelo entrevistador. Na segunda coluna, denominada "primeira associação", foram colocadas as respostas dadas às perguntas da primeira coluna, compreendendo as primeiras associações feitas sobre o tema, sem separação entre sujeito/objeto. A terceira engloba as explicações e os esclarecimentos sobre os sentidos das associações feitas a cada tema. A quarta e última coluna refere-se às falas que explicitam a afetividade das associações, incluindo sentimentos, emoções e valores atribuídos ao trabalho. A coluna é denominada de "qualificadores".

\section{QUADRO I}

MAPA DE ASSOCIAÇÃO DE IDEIAS:

O SENTIDO DO T'RABALHO PARA ENT'REVISTADO PI

\begin{tabular}{llll}
\hline OBJETO & PRIMEIRA ASSOCIAÇÃO & EXPLICAÇÃO DASASSOCIAÇÕES & QUALIFICADORES \\
\hline $\begin{array}{l}\text { Qual é o sentido do } \\
\text { trabalho para você? }\end{array}$ & & \\
\hline \multicolumn{3}{c}{$\begin{array}{l}\text { Com o trabalho a } \\
\text { gente se sente útil.. } \\
\text { sabe que serve pra } \\
\text { alguma coisa. }\end{array}$} & $\begin{array}{l}\text { A gente precisa sustentar } \\
\text { a familia, pagar contas, } \\
\text { comprar roupas, comida. }\end{array}$ \\
\hline & & & A gente se sente \\
& & & responsável. \\
\hline
\end{tabular}

Fonte: Elaborado pelos autores com base nos dados da pesquisa. 
Os mapas foram preenchidos com as respostas mais frequentes, sempre respeitando a "sequencialidade" e a dialogia, ou seja, a linha narrativa desenvolvida pela interação entre pesquisador e pesquisado. As respostas das pessoas com deficiência - que serão indicadas com a letra $P$ maiúscula seguida do número que as identifica - geraram discursos que caracterizaram seus sentidos sobre o trabalho, como demonstrado no Quadro I. Essas práticas discursivas foram objeto de análise. A categorização das respostas foi feita pela análise do discurso como um todo, pois se considerou que é o conjunto do discurso que permite a identificação do posicionamento do sujeito diante da questão que estava sendo tratada, e não o conteúdo das afirmações tomado isoladamente.

\section{OS SENTIDOS DO TRABALHO}

As referências ao sentido do trabalho apresentaram conotações diversas nos discursos dos entrevistados, essencialmente ligados a emprego ou atividade salarial, como espaço de socialização, fonte de recompensas simbólicas, tais como sentimento de utilidade, independência financeira e pessoal etc.

A análise dos discursos produzidos permitiu a criação de sete categorias a partir das quais foi possível compreender os sentidos atribuídos. Essas categorias foram: sobrevivência, necessidade de ser útil, independência financeira e pessoal, identidade social, capacitação/preparação para o trabalho, esforço pessoal e "não ter um trabalho".

A discussão dos dados por categorias acompanha alguns trechos de verbalizações dos participantes. Serão tratados apenas os temas mais presentes nos discursos das pessoas entrevistadas, e, respeitando-se a natureza do estudo qualitativo, esses resultados obtidos jamais poderão ser generalizados para a compreensão do sentido do trabalho para todas as PcD.

O trabalho foi relatado por todos os entrevistados como o eixo principal em sua vida, devido ao seu caráter instrumental, pois é por meio dele que conseguem adquirir coisas materiais e sustentar a família. O trabalho é uma forma privilegiada que o trabalhador tem para assegurar a manutenção e reprodução de sua vida. Para os entrevistados, é a independência financeira que ajuda na conquista da autonomia, pois, muito mais do que as pessoas sem deficiência, eles sempre dependeram financeiramente de seus familiares. É como se a renda obtida por meio do trabalho ajudasse na emancipação desses sujeitos. As pessoas com deficiência querem conquistar direito à vida independente, o que implica equiparação de oportunidades, como trabalho. 
Gosto muito da minha independência, tanto pessoal quanto profissional... quando se tem dinheiro, pode gastar, sabe se pode gastar, quanto dinheiro vai receber $\left(\mathrm{P}_{2}\right)$.

O trabalho muda tudo. Me sinto como um cidadão que tem o direito de comprar coisas, de chegar num lugar e passar o cartão. A pessoa poder sair e gastar o próprio dinheiro, sem ter que gastar o dinheiro dos seus pais $\left(\mathrm{P}_{3}\right)$.

É importante trabalhar para ganhar dinheiro, pois depender dos outros é muito ruim $(\mathrm{P} 7)$.

[...] todo mundo precisa pagar conta, comprar casa, roupa, calçado, sustentar os filhos (P6).

[...] preciso sustentar a família (PI).

$[\ldots]$ trabalho por precisão $\left(\mathrm{P}_{4}\right)$.

Trabalhar é importante para ganhar dinheiro, queria comprar coisas (P8).

Com o trabalho é possível ter coisas materiais (Pıo).

A independência financeira esteve sempre relacionada com a independência pessoal nos discursos. A possibilidade de planejar a própria vida, ter filhos, ter uma casa, fazer planos sobre o futuro, sair de casa sozinho para um lugar de trabalho e decidir sobre qual emprego é o melhor lugar para trabalhar são alguns aspectos relacionados a essa independência. As falas dos entrevistados reforçam que o encontro do sujeito com o trabalho impulsiona o rompimento do mito social que considera a PcD incapaz, improdutiva para a sociedade e dependente de sua família, conforme argumentam Batista, Pereira e Diniz (I997).

Como preconiza a psicodinâmica do trabalho, o sentido do trabalho para os entrevistados envolve não apenas uma atividade laboral. As experiências que o sujeito tem no e por meio do trabalho moldam sua subjetividade, provocando transformações em si mesmos: "O trabalho é importante pra mim porque me faz crescer, me faz sentir responsável, aprendi a ser responsável” (PG). 
Participar de um espaço produtivo provoca sentimento de utilidade, de estar no mundo para participar ativamente de sua construção, fazendo com que as PcD se sintam "um ser humano completo", conforme a fala de muitos. Ter uma vida produtiva, participativa, em que as capacidades pessoais e profissionais são aproveitadas, contribui para melhorar a autoestima, fazendo com que exerçam a cidadania em toda completude. Para Carvalho-Freitas, Marques e Scherer (2004), o trabalho, para uma pessoa com deficiência, representa uma dimensão interdependente da percepção que tem de si mesma e da própria vida. Esse sujeito do trabalho é também sujeito do mundo (HELLER, 2004), de modo que as experiências do trabalho contribuem significativamente para moldar a subjetividade desse trabalhador, refletindo-se na expressão desse sujeito em seu meio social.

[...] a gente serve pra alguma coisa $\left(\mathrm{P}_{4}\right)$.

[...] trabalho é ter uma vida útil ( $\left.\mathrm{P}_{5}, \mathrm{P} 6\right)$.

[...] trabalhando a gente se sente um ser humano completo (PI).

À medida que o trabalho da PcD é reconhecido pelos outros, ele torna-se visível e a PcD deixa de ser invisível para a sociedade. Segundo Lima, Hopfer e Souza-Lima (2004), o reconhecimento é a forma específica de retribuição moral-simbólica dada ao ego, como compensação por sua contribuição à eficácia da organização do trabalho. Como nos discursos abaixo, as pessoas com deficiência precisam lidar muito cedo com o sentimento de não poder fazer parte, ficando excluídas de atividades corriqueiras, mesmo na infância. $\mathrm{O}$ trabalho resgata essa possibilidade de inserção, esse sentimento de pertença à sociedade.

Ter um trabalho significa ser reconhecido pelas outras pessoas, pois você já tem que lidar com a dificuldade muito cedo, do tipo olhar os colegas andando de bicicleta, jogando na linha do gol e não poder fazer nada daquilo. Ter um trabalho significa ter importância $\left(\mathrm{P}_{3}\right)$.

Ter um trabalho é ter uma boa posição social (Pıo).

Para que esse reconhecimento ocorra, é necessário que o trabalho da PcD seja oportunizado. As habilidades para fazer algo somente se tornam evidentes quando se estabelece uma relação entre o corpo e a tarefa. 
O sentido do trabalho foi relacionado também com o seu caráter social, pois para os pesquisados, além de um meio de sobrevivência, uma fonte de renda, o trabalho se constitui em uma forma de satisfação de necessidades sociais, de se relacionar com outras pessoas, de fazer amigos, de conversar. Encontra-se aí a valorização da inserção e da relação social propiciada pelo trabalho. A integração social traz sentimentos de igualdade, que ajudam a quebrar o estereótipo social que rotula as pessoas como deficientes e incapazes. Como ressaltam Alves e Galeão-Silva (I999), a ocupação profissional é um requisito básico para a inclusão das pessoas com deficiência, não apenas por fatores econômicos que facilitam e até promovem a independência, mas também como uma forma de convívio e integração social. A participação em outros espaços, com outros indivíduos, com outras atividades, permite que as pessoas com deficiência adquiram novas experiências relacionais, o que é bastante valorizado por elas.

Porque aqui eu conheço novos amigos, pessoas diferentes (P7).

Aqui eu tenho amigos, as pessoas são legais (P6).

Ligada à identidade social, uma satisfação psicológica também se apresenta quando relatam o fato de serem reconhecidos pelos outros como trabalhadores. Isso fica expresso nos discursos quando falam do uniforme da empresa, da roupa para o trabalho, da conversa mais formal com os clientes e outros funcionários, aspectos relacionados à identidade profissional que propiciam o status de "ser trabalhador".

Aqui tem crachá, a roupa, sabe sapato? ( $\left.\mathrm{P}_{9}\right)$.

Aqui tem que trabalhar com o público e eu me adaptei bem a isso porque gosto muito de conversar. Também tem que cumprir horários e regras $(\mathrm{P} 4)$.

A necessidade de conseguir um trabalho é sentida pelas pessoas com deficiência como uma maneira de obter maior aceitação social. Mesmo com as dificuldades inerentes à inserção no mercado de trabalho relatadas pelos entrevistados, estes continuam acreditando que têm muita capacidade para o trabalho, podendo contribuir efetivamente para a empresa e a sociedade. 
Somos deficientes e não inúteis $\left(\mathrm{P}_{5}\right)$.

O sentido do trabalho está relacionado à oportunidade de mostrar minha capacidade $\left(\mathrm{P}_{2}\right)$.

Ainda é possível notar a presença do estereótipo social segundo o qual a pessoa com deficiência é considerada incapaz de realizar tarefas que as pessoas "normais" executam, conforme descrito a seguir:

No meu trabalho eu não coloco dificuldades. Se tiver que pegar uma caixa, o pessoal fala: “Deixa que eu pego”. Eu respondo: “Não, deixa que eu pego. É o meu trabalho". ( $\left.\mathrm{P}_{3}\right)$

Isso se relaciona também com a questão do estigma, com a percepção que eles construíram a respeito de si mesmos, o que corrobora a ideia de Goffman (I988), quando trata da identidade social virtual e real. Por se julgarem, desde cedo, menos capazes que outros, as PcD acreditam que encontrarão um espaço profissional que as discriminará por sua deficiência. A discrepância entre a identidade virtual e a identidade real de um indivíduo estraga a sua identidade social, pois tem como efeito afastá-lo da sociedade e de si mesmo de tal maneira que se torna uma pessoa desacreditada em um mundo não receptivo. Mas, como ressalta o próprio autor, em muitos casos ele descobrirá que há pessoas compassivas, dispostas a adotar seu ponto de vista no mundo e a compartilhar o sentimento de que ele é humano e "essencialmente" normal apesar das aparências.

Quando comecei a trabalhar, pensei que eles tinham dó de mim ( $\left.\mathrm{P}_{3}\right)$.

Ainda tratam a deficiência com preconceito. Olham pra você e acham que você não é capaz (PI).

Quando eu era adolescente percebia muito preconceito, sendo até discriminada numa entrevista. Me disseram que minha carteira estava em branco e a entrevistadora perguntou se ela era só de enfeite. Eu falei que a carteira seria preenchida quando alguém me desse uma oportunidade para trabalhar. Eu via outras pessoas com o mesmo nível de escolaridade que eu ou até menor sendo contratado e eu não (P2). 
A sociedade e, em muitos casos, a própria família julgam a PcD incapaz, reforçando tal estigma, como bem afirma esta entrevistada de 32 anos, em sua primeira experiência de trabalho:

Eu estou trabalhando agora porque meu pai e minha mãe não deixavam antes. Eu queria, mas meu pai tinha medo de eu me perder. Ele achava que eu não sabia me virar sozinha $\left(\mathrm{P}_{7}\right)$.

Muitos pais não preparam seu filho para a vida e preferem deixá-lo em casa, sem fazer nada (Pio).

Esses estereótipos e preconceitos impedem a visualização de potencialidades individuais de PcD, pois não lhes são dadas oportunidades para que suas capacidades venham à tona. $\mathrm{O}$ direito ao trabalho é um direito de cidadania, perseguido como forma de integração social pela PcD, merecedora de iguais condições de oportunidades e reconhecimento como qualquer outra. A promoção dos direitos humanos das PcD é legitimada quando essa integração vem acompanhada de iguais condições de oportunidades e reconhecimento.

As PcD afirmaram que o ambiente propiciado pelo trabalho lhes permite descobrir coisas novas por meio da rotina de trabalho. O confronto do sujeito com o trabalho possibilita a internalização das práticas sociais, a adaptação a normas e metas, o ritmo imposto de produtividade, entre outros aspectos fixados independentemente de sua vontade. O engajamento do corpo no trabalho lhe permite experimentar a execução de atividades que antes não faziam parte da sua vida diária, por meio de uma socialização profissional, que ocorre pelo treinamento na tarefa ou pela simples observação do modo de fazer de outros funcionários.

Eu aprendi só observando as pessoas fazerem (PI).

O sentido do trabalho... é importante pela independência financeira, faz a pessoa crescer, adquirir conhecimentos, ter a oportunidade de estar se aprimorando (P2).

No entanto, alguns relataram trabalhos repetitivos que não eram de seu interesse, atividades consideradas inferiores em comparação com outras desempenhadas por outras pessoas na mesma empresa. Tais atividades foram mais relatadas pelos entrevistados com deficiência mental. Nesse caso, com base no nível de comprometimento da deficiência, e a empresa provavelmente adotou planos 
de trabalho diferentes para eles, que não exigissem atendimento ao público, ou tarefas mais complexas, com alto nível de exigência intelectual. Ainda que esses sujeitos desempenhem tarefas simples, tais como arrumar o lixo, recolher e limpar bandejas, foi demonstrada a satisfação deles com a identidade social de ser um trabalhador.

Eu queria mesmo era ficar na máquina de sorvete. Todo dia tenho que arrumar lixo, limpar bandeja (P8).

Todo dia tenho que tirar chiclete debaixo da mesa que a moça deixa e limpar, limpar. Mas eu gosto de trabalhar aqui porque meu pai me vê, meus amigos também, e eu tenho um trabalho ( $\left.\mathrm{P}_{9}\right)$.

Em conformidade com a argumentação de Januzzi (I996, p. II5), o trabalho proposto às $\mathrm{PcD}$ enfatiza o disciplinamento e a aprendizagem de atividades simples da vida diária e prática, o que possibilita ao deficiente somente a ocupação de empregos não qualificados. Para essas pessoas, a possibilidade de ascender profissionalmente no sistema capitalista, em que o mercado de trabalho traz como pressuposto o mérito por habilidades, fica bastante comprometida.

Quanto à preparação/capacitação para o trabalho, os entrevistados afirmaram que fizeram alguns cursos, oferecidos pela prefeitura, Senai, Eletrobras, entre outros órgãos, todos inseridos em algum projeto voltado especificamente para a inserção de PcD no mercado de trabalho. Além disso, o tratamento em instituições hospitalares propiciou o contato com outras pessoas que também tinham deficiência e trabalhavam, despertando a potencialidade para o trabalho. $\mathrm{O}$ encaminhamento por meio de cadastro feito nos próprios hospitais propiciou a primeira experiência de trabalho para muitos deles. Isso demonstra quanto é importante a rede de contatos sociais para facilitar a inserção e a inclusão dessas pessoas no mercado de trabalho:

[...] enquanto fazia o tratamento no Hospital das Clínicas, tive contato com algumas pessoas que levavam uma vida normal, que trabalhavam, foi aí que eu vi que eu também era capaz de trabalhar (Pio).

O esforço pessoal investido para a obtenção e a manutenção do emprego foi considerado por muitos entrevistados. Procurar cursos de qualificação e tornar visíveis suas capacidades e responsabilidades com a tarefa foi considerado como "vitória" pessoal: 
Faço um monte de coisas que muitos normais não fazem. Eu tive que ralar pra estar aqui $\left(\mathrm{P}_{3}\right)$.

Trabalhei num hospital e achava que eles não valorizavam o que eu sabia fazer. Pedi demissão e saí de lá. Fiquei em casa estudando e fazendo cursos para conseguir algo melhor (Pıо).

Alguns entrevistados alegaram haver muitas PcD que não se esforçam o suficiente no trabalho, "se encostam”, nas palavras deles. Isso porque acreditam que não serão demitidas em virtude da obrigação que a empresa tem em cumprir a cota. Essa situação deixa os pesquisados em situação de desconforto, pois em muito contribui para prejudicar a imagem de quem se dedica e se esforça, reforçando a concepção de que não vale a pena contratar quem tem deficiência.

Quanto à possibilidade de não ter um trabalho, todos os entrevistados afirmaram que se sentiriam muito tristes com essa situação, pois significaria o comprometimento de tudo o que foi citado anteriormente: ter amigos, ser responsável pelo sustento familiar, adquirir coisas, status, independência, autonomia, poder de decisão sobre a própria vida, além de inúmeras outras coisas propiciadas pelo trabalho.

Ficaria muito triste, pois veria minha família com fome (PI).

Ficaria em depressão, não me imagino sem trabalho. Ficaria muito chateada (P2).

Observa-se então que o sentido do trabalho, para eles, passa por questões relacionadas à instrumentalidade do trabalho, uma vez que é por meio dele que é possível comprar coisas e adquirir autonomia financeira para sustentar a si próprio e a família. No entanto, as questões de ordem material não são suficientes para explicar todas as razões do trabalho. Para Amaral (I994b, p. I3I-I32), na sociedade capitalista o trabalho é visto essencialmente como possibilidade de inserção no circuito de produção-consumo. O potencial de elemento significativo do trabalho envolve autorrealização, autoestima, independência econômica, autonomia, prazer no processo e produto, sentimento de aceitação e pertencimento... enfim, o resgate da visão do trabalho como fonte de satisfação das pessoas com deficiência, aspectos fluentes em todos os discursos dos entrevistados.

Para todos eles, o trabalho tem valor também porque propicia novas aprendizagens, possibilidade de aprimoramento e desenvolvimento. A identidade 
pessoal e a profissional revelam-se interdependentes, uma vez que ser reconhecido pelos outros como um trabalhador lhes confere ao mesmo tempo um sentimento de diferenciação e de igualdade. Diferenciação porque, em comparação com outras pessoas com deficiência, eles se sentem vitoriosos. Igualdade porque sentem que, como os "normais", podem gozar dos mesmos privilégios de uma vida comum.

\section{CONSIDERAÇÕES FINAIS}

Neste estudo, cujo objetivo foi compreender o sentido do trabalho para pessoas com deficiência já inseridas no mercado de trabalho, observou-se a importância que o trabalho tem na vida delas, não apenas pelo seu caráter instrumental, de ganho material, mas também por outros aspectos mais subjetivos, como o sentimento de ser importante para a sociedade. Os múltiplos sentidos atribuídos ao trabalho são oriundos de experiências e vivências propiciadas pelo encontro desses sujeitos com a realidade do trabalho.

As experiências advindas da inserção da PcD no ambiente do trabalho propiciam o aprendizagem, seja pelo treinamento de habilidades para desempenho na tarefa, seja pela observação do trabalho de outras pessoas. O cumprimento de regras, normas e metas estipuladas pela empresa para todos os funcionários faz com que a PcD exerça um papel profissional e tenha um comportamento coerente com o que é estabelecido pela empresa no processo de socialização. Essas aprendizagens são internalizadas pelo sujeito e passam a integrar um conjunto de competências que o tornam mais apto até para outros trabalhos, gerando novas e melhores possibilidades de emprego.

Ser reconhecido pelos colegas do trabalho e pelas outras pessoas como um trabalhador traz um sentimento de realização e competência. Realização porque o indivíduo se reconhece como pertencente a um grupo de pessoas privilegiadas, que podem ter uma vida "normal", ou seja, a vida que uma pessoa sem deficiência teria, com família, casa, filhos, carro, emprego. Além disso, fazer o mesmo trabalho realizado por outras pessoas sem nenhuma deficiência, no mesmo espaço, contribui para essa realização profissional e gera a sensação de vitória sobre todas as dificuldades enfrentadas ao longo da vida.

As vivências no trabalho contribuem também para a produção de sentidos, principalmente quando há referências ao espaço de convivência na empresa. Os novos relacionamentos firmados com outros funcionários e com clientes permitem que as PcD saiam do isolamento social e façam parte de novos grupos que não apenas a família, a escola e o bairro. Essa inserção em outras redes de contato 
social amplia o sentimento de integração à sociedade. Aspectos como conhecer mais pessoas, deslocar-se para o emprego sozinho, ter um horário de trabalho, ter um trabalho a fazer etc. modificam a realidade dessas pessoas, que antes tinham seus espaços delimitados e eram tratadas como dependentes da ajuda de outros.

A iniciativa do governo de impor a contratação por força da Lei de Cotas é considerada benéfica, pois, sem ela, muitas PcD que hoje trabalham estariam em situação de dependência financeira e isolamento social. A lei é uma garantia de oportunidade de trabalho, pois é consenso que de outra forma seria muito mais difícil conseguir um emprego. No entanto, vale ressaltar que o esforço pessoal e o interesse em aprender são fundamentais para conseguir um trabalho e manter-se empregado, para qualquer pessoa, com ou sem deficiência.

As reflexões contidas neste trabalho, além de apresentarem alguns fatores relacionados ao sentido do trabalho, revelaram a necessidade de desenvolvimento de novas pesquisas de caráter longitudinal. Sugere-se a realização de estudos mais aprofundados sobre as histórias da inserção das pessoas com deficiências no mercado de trabalho, de modo a revelar toda a subjetividade que marca a participação desses sujeitos sociais no contexto do trabalho.

\section{THE MEANING OF WORK FOR PERSONS WITH DISABILITY}

\section{ABSTRACT}

This research aims to analyze the meaning of work for people with disability (PwD). We chose to adopt the perspective of social psychology to understand the production of meanings related to work because of his relationship with the production of subjectivity. The size of the work as a social reality, as well as claims Dejours (2004), it is essential to human activity, contributing not only to the satisfaction of economic needs, but also psychological and social. For the $\mathrm{PwD}$, the study of this assigning senses becomes compelling as the work has been considered an important means of inclusion of these people in society. We adopted a qualitative research for understanding the production of meaning, with the analysis of discursive practices and techniques of interview partners (Spink, 2004). Social constructionism was used as a research method. We conducted ten interviews with disabled people entered the labor market chosen by snowball technique. For the analysis procedure, there was an adaptation of the feature 
maps of the association of ideas used by Spink (I999). The analysis allowed the elaboration of the categories survival, need to be useful, financial and personal independence, social identity, job training, personal effort and "not having a job." It was observed in the discursive productions in the centrality of work all their lives, while for some more related to survival and for others, social inclusion. The experiences at work are related to feelings of capability and usefulness to society. This work allowed us to understand that the regularities found in the discursive repertoires refer the meaning of work for the full exercise of citizenship.

\section{KEYWORDS}

Labor; Disability; Diversity; Senses; Inclusion.

\section{EL SIGNIFICADO DEL TRABAJO PARA LAS PERSONAS CON DISCAPACIDAD}

\section{RESUMEN}

Esta investigación tiene como objetivo analizar el significado del trabajo para las personas con discapacidad (PCD). Optamos por adoptar la perspectiva de la psicología social para entender la producción de significados relacionados con el trabajo debido a su relación con la producción de subjetividad. El tamaño de la obra como una realidad social, como bien dice Dejours (2004), es esencial a la actividad humana, contribuyendo no sólo a la satisfacción de las necesidades económicas, sino también psicológica y sociales. Para PcD, el estudio de esta atribución de sentido se hace inevitable que el trabajo ha sido considerado como un medio importante para la inclusión social de estas personas en la sociedad. Para el desarrollo de la investigación cualitativa que tuvo como resultado este artículo se optó por el método de análisis de las prácticas discursivas, los supuestos ontológicos y epistemológicos que se anclan en el enfoque descrito por Spink sóciocontrucionista (2004). Adoptamos la investigación cualitativa para entender la producción de sentido, con el análisis de discursas prácticas. El construccionismo social se utilizó como método de investigación. Se llevaron a cabo entrevistas en profundidad con personas con discapacidad en el mercado laboral elegido por la técnica de bola de nieve. Para el procedimiento, se produjo una adaptación de los mapas de características de la asociación de ideas utilizadas por Spink (I999). El análisis ha permitido el desarrollo de la supervivencia de las categorías, deben 
ser útiles la independencia, financiera y de la identidad personal, social, capacitación para el trabajo, el esfuerzo personal y "no tienen un trabajo." Se observó en las producciones discursivas la centralidad del trabajo en las vidas de todos ellos, siendo, para algunos, más relacionado con la supervivencia, y para otros, la inclusión social. Las experiencias en el trabajo están relacionadas con los sentimientos de la capacidad y utilidad para la sociedad. Este trabajo permitió comprender que las regularidades que se encuentran en los repertorios discursivos se refieren al significado del trabajo para el ejercicio pleno de la ciudadanía.

\section{PALABRAS CLAVE}

Trabajo; Discapacidad; Diversidad; Sentidos; Inclusión.

\section{REFERÊNCIAS}

AGUIAR, W. M. J. (Org.). Sentidos e significados do professor na perspectiva sócio-histórica: relatos de pesquisa. São Paulo: Casa do Psicólogo, 2006.

ALVES, M. A.; GALEÃO-SILVA, L. G. A crítica da gestão da diversidade nas organizações. Revista de Administração de Empresas, v. 44, n. 3, p. 20-29, jul./set. 2004.

AMARAL, L. A. Resgatando o passado: deficiência como figura e vida como fundo. São Paulo: Casa do Psicólogo, I994a.

AMARAL, L. A. Pensar a diferença/deficiência. Brasília: Coordenadoria Nacional para Integração de Pessoa Portadora de Deficiência, I994b.

BARNES, C.; MERCER, G. Disability, work, and welfare: challenging the social exclusion of disabled people. Work, Employment \& Society, v. I9, n. 3, p. 527-545, 2005.

BATISTA, C. A. M.; PEREIRA, M. S.; DINIZ, J. Educação profissional e colocação no trabalho: uma nova proposta de trabalho junto à pessoa portadora de deficiência. Brasília: Federação Nacional das Apaes, I997.

BRASIL. Ministério do Emprego e do Trabalho. Lei n. 8.ıI2 de II de dezembro de I990. Legislação relativa ao trabalho de pessoas portadoras de deficiência: coletânea. Brasília: MTE, SIT/DSST, I999a. BRASIL. Ministério do Emprego e do Trabalho. Lei n. 8.213 de 24 de julho de I991. Legislação relativa ao trabalho de pessoas portadoras de deficiência: coletânea. Brasília: MTE, SIT/DSST, I999b. CARVALHO-FREITAS, M. N. Inserção e gestão do trabalho de pessoas com deficiência: um estudo de caso. Revista de Administração Contemporânea, v. I3, Edição Especial, p. I2I-I38, 2009.

CARVALHO-FREITAS, M. N.; MARQUES, A. L.; SCHERER, F. L. Inclusão no mercado de trabalho: um estudo com pessoas portadoras de deficiência. In: ENCONTRO DA ASSOCIAÇÃO NACIONAL DE PÓS-GRADUAÇÃO E PESQUISA EM ADMINISTRAÇÃO, 28., 2004, Curitiba. Anais eletrônicos... Curitiba: Anpad, 2004. CD-ROM.

DEJOURS, C. Travail, usure mentale. De la psychopatologie du travail à la psychodynamique du travail. Paris: Bayard, I993. 
DEJOURS, C. Psychologie clinique du travail et tradition compréhensive. In: CLOT, Y. Les histoires de la psychologie du travail. Approche pluri-disciplinaire. Toulouse: Octares, I999.

DEJOURS, C. Addendum: da psicopatologia à psicodinâmica do trabalho. In: LANCMAN, S.; SZNELWAR, L. I. (Org.). Christophe Dejours: da psicopatologia à psicodinâmica do trabalho. Rio de Janeiro: Fiocruz; Brasília: Paraleloı5, 2004.

ENRIQUEZ, E. Instituições, poder e desconhecimento. In: ARAÚJO, J. N. G.; CARRETEIRO, T. Cenários sociais e abordagem clínica. São Paulo: Escuta; Belo Horizonte: Fumec, 200I.

ESTEVES, S. A. P. O dragão e a borboleta: sustentabilidade e responsabilidade social nos negócios. São Paulo: Axis Mundi, AMCE, 2000.

FLEURY, M. T. Gerenciando a diversidade cultural: experiências de empresas brasileiras. RAE Revista de Administração de Empresas, v. 40, n. 3, p. I8-25, jul./set. 2000.

GOFFMAN, E. Estigma: notas sobre a manipulação da identidade deteriorada. 4. ed. Rio de Janeiro: Zahar, I988.

GONZÁLEZ REY, F. Sujeito e subjetividade: uma aproximação histórico-cultural. São Paulo: Pioneira, Thomson Learning, 2003.

HELLER, A. O cotidiano e a história. 7. ed. São Paulo: Paz e Terra, 2004.

JANUZZI, G. S. M. Deficiência mental, cidadania e política. Temas em Educação Especial, São Carlos, n. 3, p. I07-II8, I996.

LEONTIEV, A. O desenvolvimento do psiquismo. São Paulo: Centauro, 2004.

LIMA, S. M. M.; HOPFER, K. R.; SOUZA-LIMA, J. E. Gestão de pessoas - complementaridade entre racionalidades na construção da identidade profissional. RAE-eletrônica, v. 3, n. 2, jul./dez. 2004.

MCLAUGHLIN, M. E.; BELL, M. P.; STRINGER, D. Y. Stigma and acceptance of persons with disabilities: understudied aspects of workforce diversity. Group \& Organization Management, v. 29, n. 3, p. 302-333, 2004 .

MEANING OF WORK INTERNATIONAL RESEARCH TEAM. The meaning of working. London: Academic Press, I987.

MILLER, E. Positivism and clinical psychology. Clinical Psychology and Psychotherapy, v. 6, p. I-6, I999.

MORIN, E. M. Os sentidos do trabalho. Revista de Administração de Empresas, v. 4I, n. 3, p. 8-I9, 200 I. NARDI, H. C.; TITTONI, J.; BERNARDES, J. Subjetividade e trabalho. In: CATTANI, A. D. Dicionário crítico sobre trabalho e tecnologia. 2. ed. Petrópolis: Vozes, I997. p. 240-246.

POTTER, J.; WETHERELL, M. Discourse and social psychology: beyond attitudes and behaviour. London: Sage, 1987.

SIMONI, M. Trabalhar é preciso: reflexões sobre o conceito de trabalho humano e suas implicações para a engenharia de produção. I996. Tese (Doutorado em Engenharia de Produção)-Universidade Federal do Rio de Janeiro, Rio de Janeiro, I996.

SPINK, M. J. Práticas discursivas e produção de sentidos no cotidiano: aproximações teóricas e metodológicas. São Paulo: Cortez, I999.

SPINK, M. J. (Org.). Práticas discursivas e produção de sentidos no cotidiano: aproximações teóricas e metodológicas. São Paulo: Cortez, 2004.

SPINR, M. J.; LIMA, H. Rigor e visibilidade: a explicitação dos passos da interpretação. In: SPINR, M. J. (Org.). Práticas discursivas e produção de sentidos no cotidiano: aproximações teóricas e metodológicas. 3. ed. São Paulo: Cortez, 2004. 
SPINK, M. J.; MEDRADO, B. Produção de sentidos no cotidiano: uma abordagem teórico metodológica para análise das práticas discursivas. In: SPINK, M. J. P. Práticas discursivas e produção de sentidos no cotidiano: aproximações teóricas e metodológicas. São Paulo: Cortez, 2004.

SUZANO, J. C. C. et al. Análise da produção acadêmica nacional dos últimos 20 anos sobre a inserção da pessoa portadora de deficiência no mercado de trabalho. In: CARVALHO-FREITAS, M. N.; MARQUES, A. L. Trabalho e pessoas com deficiência: pesquisas, práticas e instrumentos de diagnóstico. Curitiba: Juruá, 2008.

TANAKA, E. D. O.; MANZINI, E. J. O que os empregadores pensam sobre o trabalho da pessoa com deficiência. Revista Brasileira de Educação Especial, v. II, n. 2, p. 273-294, 2005.

TOLFO, S. da R.; PICCININI, V. C. Sentidos e significados do trabalho: explorando conceitos, variáveis e estudos empíricos brasileiros. Psicologia \& Sociedade, v. I9, Edição Especial I, p. 38-46, 2007. VYGOTSKY, L. S. A construção do pensamento e da linguagem. São Paulo: Martins Fontes, 200 I. 